03,12

\title{
Влияние висмута на структурное совершенство и люминесцентные свойства тонкопленочных упругонапряженных гетероструктур $\mathrm{Al}_{x} \operatorname{In}_{y} \mathrm{Ga}_{1-x-y} \mathrm{Bi}_{z} \mathrm{Sb}_{1-z} / \mathrm{GaSb}$
}

\author{
() Д.Л. Алфимова ${ }^{1}$, М.Л. Лунина ${ }^{1}$, Л.С. Лунин ${ }^{1,2, \uparrow ~, ~ А . С . ~ П а щ е н к о ~}{ }^{1}$, А.Е. Казакова ${ }^{2}$ \\ ${ }^{1}$ Южный научный центр РАН, \\ Ростов-на-Дону, Россия \\ ${ }^{2}$ Южно-Российский государственный политехнический университет (НПИ) им. М.И. Платова, \\ Новочеркасск, Россия \\ 『E-mail: lunin_Is@mail.ru \\ (Поступила в Редакцию 14 июня 2017 г. \\ В окончательной редакции 27 декабря 2017 г.)
}

Исследовано влияние висмута на структурное совершенство и люминесцентные свойства гетероструктур $\mathrm{Al}_{x} \mathrm{In}_{y} \mathrm{Ga}_{1-x-y} \mathrm{Bi}_{z} \mathrm{Sb}_{1-z} / \mathrm{GaSb}$. Выявлены оптимальные параметры процесса зонной перекристаллизации градиентом температур, при которых эпитаксиальные слои AlInGaBiSb имели минимальную шероховатость и высокое структурное совершенство: градиент температуры $1 \leq G \leq 30 \mathrm{~K} / \mathrm{cm}$, толщина жидкой зоны $60 \leq l \leq 100 \mu \mathrm{m}$, температурный интервал $773 \leq T \leq 873 \mathrm{~K}$ и концентрация висмута $0.3-0.4 \mathrm{~mol}$. frac.

Работа выполнена в рамках госзадания грант № 16.4757.2017/8.9, а также при финансовой поддержке Российского фонда фундаментальных исследований по гранту 17-08-01206 а.

DOI: 10.21883/FTT.2018.07.46109.194

\section{1. Введение}

Гетероструктуры на основе многокомпонентных твердых растворов соединений $A^{3} B^{5}$ широко используются для создания оптоэлектронных приборов [1-5]. Изменение ширины запрещенной зоны при сохранении периода решетки является важнейшим преимуществом четверных твердых растворов (ЧТР) соединений $A^{3} B^{5}$ перед тройными [6-10]. Однако, такое ограничение, как термодинамическая неустойчивость многокомпонентных твердых растворов, приводящая к их спинодальному распаду, сужает область изопериодных составов ЧТР [11-14]. Таким образом, чтобы перекрыть весь диапазон ИК-спектра необходимо использовать пятерные твердые растворы (ПТР) соединений $A^{3} B^{5}$ [15].

Использование в гетероструктурах изовалентных компонентов, активно влияющих на зонную структуру эпитаксиальных слоев (таких, как азот, висмут), открывает широкие возможности в управлении спектром люминесценции, и структурным совершенством [16-20]. Применение висмута в качестве изовалентной примеси дает ряд преимуществ, таких как: улучшение морфологической стабильности фронта кристаллизации и уменьшение отклонения состава соединений $A^{3} B^{5}$ от стехиометрии, возможность изменения коэффициентов распределения легирующих компонент за счет взаимодействия примесей в расплаве [21]. Увеличение компонентов в многокомпонентных твердых растворах (МРТ) и легировании изовалентными примесями (Bi) открывает широкие возможности в варьировании фотоэлектрических свойств элементной базы приборов [22-27]. Кроме того, висмутосодержащие многокомпонентные гетероструктуры на основе антимонида галлия интересны также для создания фотоприемных устройств, работающих в спектральном диапазоне 0.4-4.0 $\mu \mathrm{m}$ [28-30].

Цель настоящей работы - выращивание тонких эпитаксиальных слоев AlInGaBiSb на подложках $\mathrm{GaSb}$ и исследование влияния висмута на структурное совершенство и люминесцентные свойства гетероструктур $\mathrm{Al}_{x} \mathrm{In}_{y} \mathrm{Ga}_{1-x-y} \mathrm{Bi}_{z} \mathrm{Sb}_{1-z} / \mathrm{GaSb}$.

\section{2. Экспериментальная часть}

Выращивание висмутосодержащих гетероструктур проводили методом зонной перекристаллизации градиентом температуры (ЗПГТ) в закрытой системе в потоке водорода, очищенного в процессе диффузии через палладий [31]. В качестве жидкой зоны использовали растворрасплав из чистых элементов $\mathrm{Sb}(\mathrm{CУ}-000), \operatorname{In}(И Н-000)$, $\mathrm{Ga}($ ГЛ-000), $\mathrm{Bi}($ ВИ-000), $\mathrm{Al}$ (АЛ-000). Расчет навесок проводился по методике, описанной нами ранее [32,33], с учетом молярных масс элементарных компонентов. Все материалы кроме галлия, подвергались химической обработке в смеси $\mathrm{HNO}_{3}: \mathrm{H}_{2} \mathrm{O}(1: 1)$, промывке в дистиллированной воде и сушке в термостате при температурах $333-343 \mathrm{~K}$.

В качестве подложек для выращивания эпитаксиальных слоев AlInGaBiSb использовали монокристаллические пластины $\mathrm{GaSb}$ с электронным типом проводимости, ориентированные в кристаллографических плоскостях (100) и (111) с точностью не хуже $10^{\prime}$. Использовали подложки $\mathrm{GaSb}$, легированные теллуром до кон- 
центрации $n=(1-5) \cdot 10^{17} \mathrm{~cm}^{-3}, \quad\left(\mu \sim 5700 \mathrm{~cm}^{2} / \mathrm{V} \cdot \mathrm{s}\right)$. Плотность дислокаций в подложке не превышала $5 \cdot 10^{3} \mathrm{~cm}^{-2}$. Перед процессом эпитаксии подложки $\mathrm{GaSb}$ обрабатывали по следующей методике:

- обезжиривание этиловым спиртом $\left(\mathrm{C}_{2} \mathrm{H}_{5} \mathrm{OH}\right)$; - обработка в травителе (смесь $20 \%$ водного раствора винной кислоты, перекиси водорода и плавиковой кислоты $\mathrm{H}_{2} \mathrm{C}_{4} \mathrm{H}_{4} \mathrm{O}_{5}: \mathrm{H}_{2} \mathrm{O}_{2}: \mathrm{HF}=25: 12: 1$ в течении $\left.1.5-3 \mathrm{~min}\right)$; - промывка в дистиллированной воде;

- сушка в термостате при температуре $333 \mathrm{~K}$.

Определение несоответствия параметров решеток подложки и слоя и оценка кристаллического совершенства гетероструктур осуществлялась методом регистрации рентгеновской дифракции. Съемка кривых дифракционного отражения (КДО) рентгеновского излучения проводилась на высокоразрешающем рентгеновском дифрактометре ТPC-1 в двухкристальной геометрии. Источником излучения служила рентгеновская трубка с медным анодом $\left(\mathrm{Cu} K_{\alpha 1}, \lambda=1.54 \AA\right)$. Помимо измерения $\Delta a$, определяли и анализировали полуширины КДО от эпитаксиального слоя и подложки. Учитывалась также форма дифракционных кривых и наличие (отсутствие) интерференционных максимумов, несущих информацию о качестве поверхности слоя и планарности границы раздела слой/подложка.

Составы полученных твердых растворов определяли на рентгеновском микрозондовом анализаторе Camebax при ускоряющем напряжении $20 \mathrm{kV}$ и токе первичного пучка $0.1-1.0 \mu \mathrm{A}$. Погрешность измерений не превышала $\pm 0.01 \%$ для тяжелых элементов (с атомным номером более 25$)$ и $\pm 0.1 \%$ для легких элементов, при их содержании в образце в количестве $0.1 \mathrm{~mol}$. frac.

Оже-электронные спектры получены на спектрометpe ЭСО-3 с энергоанализатором типа „цилиндрическое зеркало“. Энергетическое разрешение, измеренное по пику упруго отраженных электронов, составляло $0.25 \%$. Измерения проводили при ускоряющем напряжении электронной пушки $3 \mathrm{kV}$ и токе пучка $3 \mu \mathrm{A}$, при этом диаметр пучка составлял $5 \mu \mathrm{m}$. Давление остаточных газов в камере спектрометра при измерениях $10^{-7} \mathrm{~Pa}$.

Исследования упругих напряжений в эпитаксиальных слоях AllnGaBiSb проводились на основе стандартного поляризационно-оптического метода. Использовался инфракрасный микроскоп МИК-11 с электроннооптическим преобразователем ЭОП-4 в поляризованном свете.

Измерения фотолюминесценции проводили в спектральном диапазоне от 950 до $1500 \mathrm{~nm}$ при температуре $300 \mathrm{~K}$ и в жидком азоте при $77 \mathrm{~K}$ в криостате с кварцевыми окнами. В качестве источника возбуждающего оптического излучения использовался инжекционный лазер с длиной волны $402 \mathrm{~nm}$ и мощностью излучения $8.5 \mathrm{~mW}$. Фотодетектором служил германиевый фотодиод ФПУ ФДГ с рабочим спектральным диапазоном длин волн от 0.5 до $2 \mu \mathrm{m}$. Возбуждение фотолюминесценции осуществлялось со стороны эпитаксиальных слоев.
Шероховатость измеряли в полуконтактном режиме на сканирующем зондовом микроскопе Solver HV. Для измерений использовали кантилеверы серии HA_HR c радиусом закругления менее $10 \mathrm{~nm}$. Проводилось сканирование трех различных участков образца. Шероховатость поверхности характеризовали средним арифметическим отклонением профиля $R_{a}$ и высотой неровностей $R_{z}$ по десяти точкам.

\section{3. Результаты и их обсуждение}

Жидкая фаза зоны при ЗПГТ служит транспортной средой при переносе ростового вещества от источника к подложке. Одновременно жидкая зона активно влияет на состав растущего слоя. Поэтому в общем случае состав растущего слоя не воспроизводит состав источника. Это объясняется вхождением в растущие слои атомов основного вещества зоны, массообменном между жидкой и газовой средами, изменением в процессе ЗПГТ толщины зоны и ее температуры, неодинаковостью составов источника и подложки. Последний фактор проявляется главным образом на первой стадии процесса ЗПГТ и зависит от особенности этапа образования композиции источник-зона-подложка. Компоненты первоначально растворившихся слоев источника максимально разбавлены веществом зоны и входят в растущие слои в минимальной концентрации. Компоненты растворившихся слоев подложки первоначально входят в растущие слои в максимальной концентрации, а затем эта концентрация уменьшается до нуля.

Массообмен с окружающей газовой средой важен для летучих компонентов и полностью исчезает, если жидкая зона погружается в объем кристалла. Варьирование толщины зоны в процессе ЗПГТ может изменить концентрацию растворенных в ней компонентов и, следовательно, состав растущих слоев. Однако этот эффект незначителен. Невелико также влияние на состав растущего слоя изменения температуры жидкой фазы, связанного с перемещением зоны в процессе ЗПГТ в более нагретые части кристалла. Намеренные колебания температуры зоны могут привести к значительным изменениям состава как на стадии возникшего переходного процесса, так и в стационарном режиме.

В стационарных условиях ЗПГТ состав растущего слоя близок к равновесному и определяется диаграммой состояния системы. Как правило, для многокомпонентных зон они исследованы недостаточно. Поэтому при расчетах состава выращенных слоев необходимо опираться на значения расчетных и экспериментальных коэффициентов распределения. Результаты оже-анализа тонкопленочных гетероструктур $\mathrm{Al}_{x} \mathrm{In}_{y} \mathrm{Ga}_{1-x-y} \mathrm{Bi}_{z} \mathrm{Sb}_{1-z} / \mathrm{GaSb}$, показали, что на поверхности эпитаксиальных пленок AlInGaBiSb присутствуют все компоненты (рис. $1, a$ ). До глубины $600 \mathrm{~nm}$ наблюдается быстрое убывание концентрации $\mathrm{Al}$ и медленное снижение $\mathrm{Sb}$. Концентрация остальных компонентов In, 

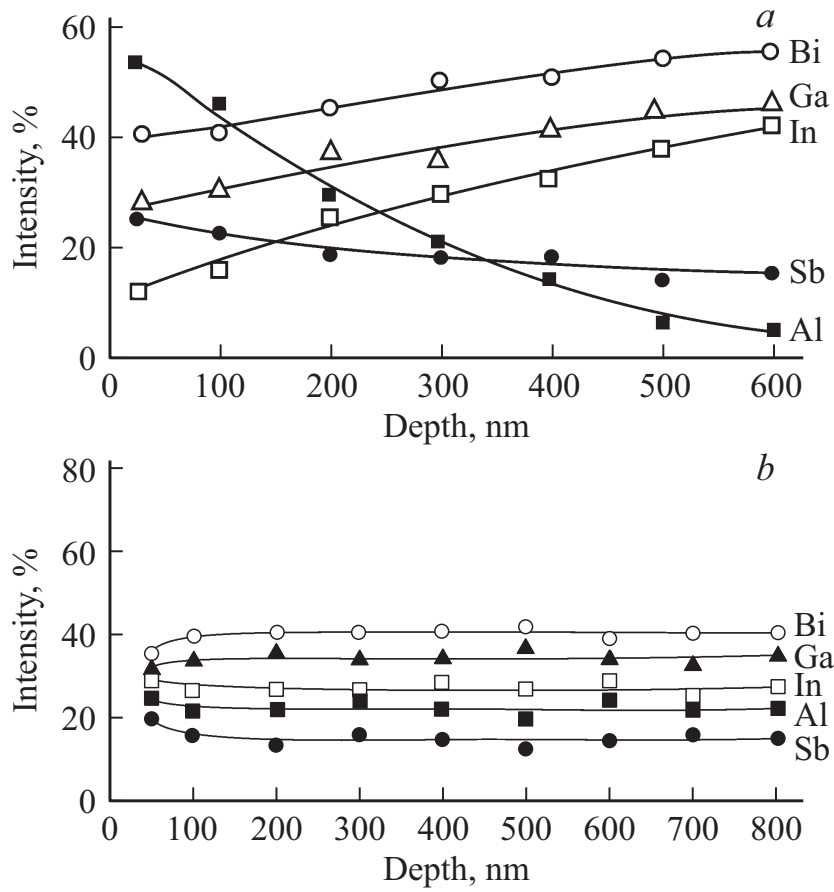

Рис. 1. Профиль распределения элементов по глубине гетероструктуры AlInGaBiSb/GaSb: $a-$ без подпитки, $b-\mathrm{c}$ подпиткой из поликристалла $\mathrm{AlGaSb}$.

$\mathrm{Ga}$ и Вi постепенно увеличивается. Это связанно с зависимостью коэффициентов распределения компонентов от их содержания в жидкой зоне [16].

Исследования показали, что коэффициенты распределения алюминия, галлия и сурьмы увеличиваются с ростом концентрации алюминия, а для индия и висмута уменьшаются. Небольшое значения коэффициентов распределения индия, сурьмы и очень малое значение коэффициента распределения висмута, делает возможным получение твердого раствора AlInGaBiSb из галлиевой жидкой зоны, обогащенной висмутом. Учитывая большой коэффициент распределения алюминия необходима его подпитка из источника. Например, для этого используется поликристалл $\mathrm{AlGaSb}$, что позволяет вырастить гетероструктуры постоянного состава (рис. $1, b$ ). Без подпитки практически по всей толщине слоя распределение компонентов меняется и получаются варизонные гетероструктуры AllnGaBiSb/GaSb (рис. 1,a).

При гетероэпитаксии за счет рассогласования периода решеток и коэффициентов термического расширения (КТР) слоя и подложки возникают дислокации несоответствия, значительная доля которых перемещается в объем пленки и появляется на поверхности гетероструктур при достижении некоторого критического значения упругих напряжений [16]. Исследования многокомпонентных гетероструктур соединений $A^{3} B^{5}$ показали, что качество поверхности и структурное совершенство зависит от условий выращивания [32]. Результаты измерений ширины линий качания и дифракционного отражения $B_{H / 2}^{\prime \prime}$ для гетероструктур выращенных при различных градиентах температуры и толщине жидкой зоны, представлены на рис. 2. Видно, что с увеличением градиента температуры увеличивается ширина дифракционных кривых на половине высоты $B_{H / 2}^{\prime \prime}$ (кривые 1,2 ), что указывает на ухудшение совершенства гетероструктур $\mathrm{AlInGaBiSb} / \mathrm{GaSb}$. Это связано с нарушением теплового и диффузионного равновесия, вследствие чего ухудшается стабильность фронта кристаллизации и появляются микровключения на гетерогранице [16]. Сравнение кривых 1 и 2 показывает, что при увеличении концентрации висмута в расплаве улучшается совершенство гетероструктур при всех градиентах температуры. Это обусловлено тем, что при росте концентрации висмута в расплаве повышается морфологическая стабильность фронта кристаллизации [32,33]. Результаты исследований от толщины жидкой зоны (рис. 2 , кривые 3,4 ) показали, что с увеличением $l$ уменьшается $B_{H / 2}^{\prime \prime}$ и, следовательно, совершенство гетероструктур AlInGaBiSb/GaSb улучшается за счет равномерного растворения и распределения компонентов в расплаве и, соответственно, у гетерограницы, что позволяет проводить кристаллизацию твердого раствора AllnGaBiSb стехиометрического состава. При достаточно тонких зонах толщиной менее $80 \mu \mathrm{m}$ не происходит полного растворения зерен перекристаллизуемого источника. В результате в тонких пленках наблюдаются нановключения и, соответственно, нарушения планарности гетерограницы и однородности по составу. Дополнительную морфологическую стабильность фронта кристаллизации добавляет увеличение концентрации висмута в расплаве, что приводит к умень-

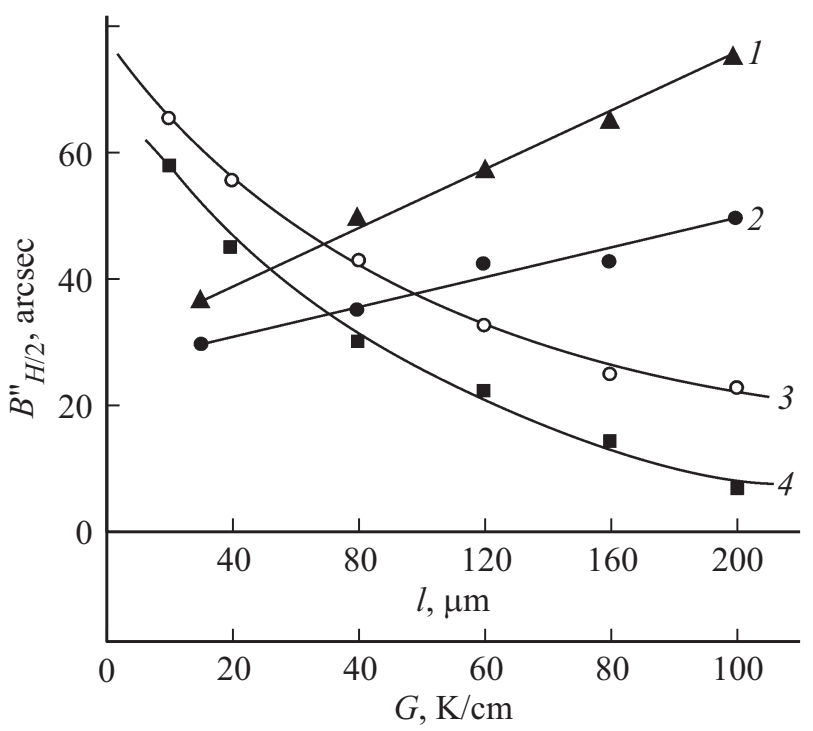

Рис. 2. Зависимость ширины спектра КДО на половине высоты $B_{H / 2}^{\prime \prime}$ для гетероструктур $\mathrm{Al}_{x} \mathrm{In}_{y} \mathrm{Ga}_{1-x-y} \mathrm{Bi}_{z} \mathrm{Sb}_{1-z} / \mathrm{GaSb}$ от градиента температуры $G$ и толщины жидкой зоны $l$ для различных концентраций висмута: $1-z=0.05$; $2-z=0.4$ mol. frac. при $l=70 \mu \mathrm{m}, T=787 \mathrm{~K} ; 3-z=0.05$, $4-z=0.4 \mathrm{~mol}$. frac. при $G=35 \mathrm{~K} / \mathrm{cm}$. 


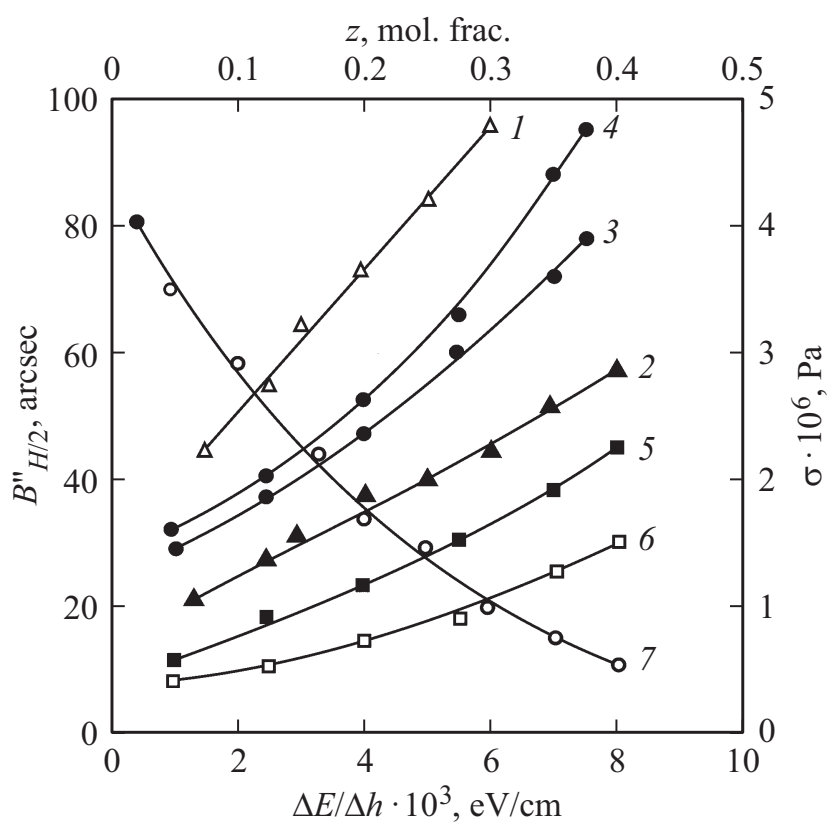

Рис. 3. Зависимости ширины спектра КДО на половине высоты $B_{H / 2}^{\prime \prime}$ (кривые $1-z=0.1,2-z=0.4$ ) и величины упругих напряжений $(\sigma)$ варизонных гетероструктур $\mathrm{Al}_{x} \mathrm{In}_{y} \mathrm{Ga}_{1-x-y} \mathrm{Bi}_{z} \mathrm{Sb}_{1-z} / \mathrm{GaSb}$ (кривые 3, 6 - подложки, 4, 5 слой) от градиента ширины запрещенной зоны $\Delta E / \Delta h(3,4$ при $z=0.2 ; 5,6$ при $z=0.4)$. Кривая $7-$ зависимость $B_{H / 2}^{\prime \prime}$ от $z$ гетероструктур $\mathrm{Al}_{x} \operatorname{In}_{y} \mathrm{Ga}_{1-x-y} \mathrm{Bi}_{z} \mathrm{Sb}_{1-z} / \mathrm{GaSb}$ постоянного состава. Кривые $1-7$ сняты для гетероструктур, выращенных при $T=787 \mathrm{~K}, G=60 \mathrm{~K} / \mathrm{cm}, l=80 \mu \mathrm{m}$.

шению $B_{H / 2}^{\prime \prime}$ и улучшению совершенства гетероструктур AlInGaBiSb/GaSb для всех толщин зон (рис. 2, кривая 4).

Различие $\Delta a$ и $\Delta \alpha$ в слое и подложке приводит к механическим напряжениям, возникающим в кристаллизуемом материале непосредственно в процессе роста, либо во время последующего охлаждения до комнатной температуры [15-34].

Висмут образует твердый раствор замещения в подрешетке сурьмы, деформируя решетку по типу растяжения [16,17]. Аналогичный эффект наблюдается при росте числа антиструктурных дефектов $\mathrm{Bi}_{\mathrm{Ga}}$ и $\mathrm{Bi}_{\mathrm{In}}$. Внедрение атомов Вi в междоузлия приводит к изгибу гетероструктуры в сторону кристаллизующегося слоя. При введении в твердый раствор алюминия в гетероструктуре AlInGaBiSb/GaSb возможна частичная компенсация решеточных несоответствий [16]. Понизить напряженное состояние гетероперехода можно, повышая морфологическую стабильность фронта кристаллизации и уменьшая концентрацию собственных точечных дефектов при увеличении висмута в расплаве (рис. 3, кривая 7). Сравнение кривых 1,4,5 с кривыми 2, 3, $\dot{6}$ свидетельствует о дефектоподавляющей роли висмута в расплаве.

В случае наращивания варизонных слоев AlInGaBiSb дополнительным источником упругих напряжений может служить наличие значительных градиентов состава по толщине слоев $d C / d h$. Напряжения, возникающие при наличии градиента состава $G_{d C}$, могут быть обусловлены градиентом периода решетки (как по толщине, так и по поверхности слоя). Вклад этой причины дефектности становится заметным лишь при наличии резких градиентов состава $(d C / d h)$. Связь величин $G_{d C}$ и $d C / d h$ может быть представлена следующим выражением [15]:

$$
G_{d C}=\frac{\beta E}{1-\gamma} \frac{d C}{d h}
$$

где $\beta-$ коэффициент, учитывающий изменение $a$ и $\alpha$ в пределах изменения состава, $E$ - модуль упругости, $\gamma$ - коэффициент Пуассона.

Как было показано выше (рис. 1,a) для варизонных гетероструктур AlInGaBiSb/GaSb изменяются по толщине слоя все компоненты. Поэтому построены зависимости $B_{H / 2}^{\prime \prime}$ и $\sigma$ от градиента ширины запрещенной зоны (рис. 3). Видно, что с увеличением градиента ширины запрещенной зоны $B_{H / 2}^{\prime \prime}$ повышается и совершенство слоев AlInGaBiSb значительно ухудшается и тем быстрее, чем больше $d C / d h$ в слое. Сравнение зависимостей $1,4,5$ и 2,3,6 показывает, что с увеличением содержания висмута она становится менее резкой и значительно ниже дефектность гетероструктур AlInGaBiSb. Это связано с тем, что атомы Bi в расплаве, объединяясь в комплексы с большой длиной квазихимической связи, выполняют функцию „молекулярного сита“, т.е. упорядочивают перемещение атомов кристаллизующегося твердого раствора в направление гетерограницы. Кроме того, висмут занимает позиции $\mathrm{Sb}$ в подрешетке сурьмы. Такое поведение Ві восполняет стехиометрический недостаток сурьмы и препятствует смещению галлия под решетку $\mathrm{Sb}$. Вакансии сурьмы в межузельный галлий считаются основными дефектами

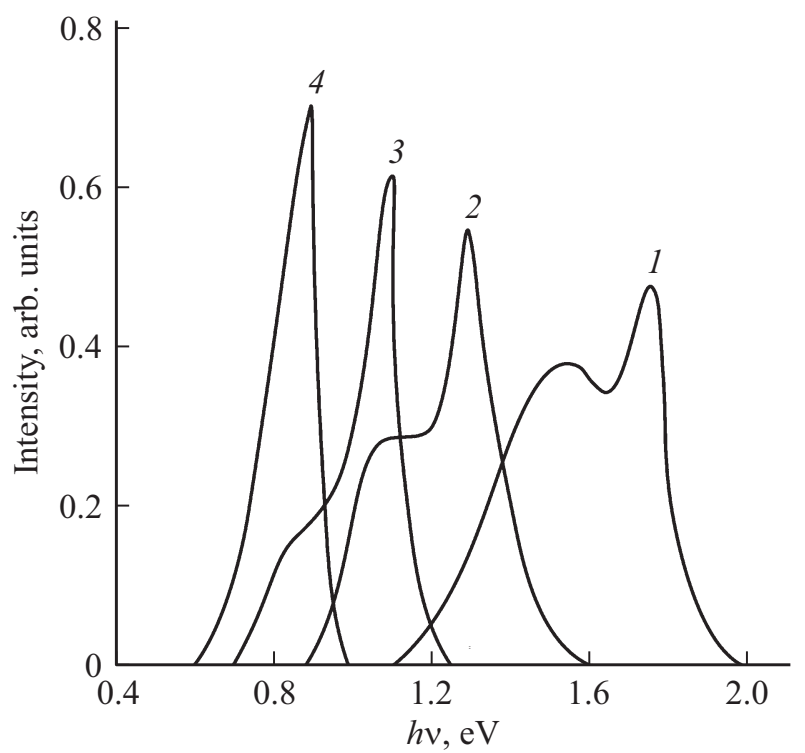

Рис. 4. Спектры фотолюминесценции эпитаксиальных слоев $\mathrm{Al}_{x} \mathrm{In}_{y} \mathrm{Ga}_{1-x-y} \mathrm{Bi}_{z} \mathrm{Sb}_{1-z}$ (77 K) при концентрации висмута $z$ : $1-0.0,2-0.1,3-0.2,4-0.4$ mol. frac. 
нестехиометрии в твердых растворах на основе антимонида галлия. Висмут снижает концентрацию вакансии сурьмы, уменьшая тем самым вероятность образования „антиструктурного“ дефекта $\mathrm{V}_{\mathrm{Ga}} \mathrm{Ga}$ sь и отклонение состава от стехиометрии [35]. О снижении концентрации вакансий сурьмы и уменьшении образования „антиструктурных“ дефектов с увеличением концентрации висмута свидетельствуют спектры фотолюминесценции гетероструктур AlInGaBiSb/GaSb (рис. 4).

Монотонное смещение энергетического пика $E_{g}$ в длинноволновую область с ростом содержания висмута в эпитаксиальных слоях AlInGaBiSb обусловлено уменьшением ширины запрещенной зоны. Кроме того, по мере увеличения концентрации висмута в слоях $\mathrm{AlInGaBiSb}$ уменьшается интенсивность низкоэнергетического пика $E_{V}$, связанного с появлением акцепторных комплексов $\left(\mathrm{V}_{\mathrm{Ga}} \mathrm{Ga}_{\mathrm{Sb}}\right)$. Такое перераспределение интенсивности люминесценции, по-видимому, связано как с уменьшением концентрации комплексов $\left(\mathrm{V}_{\mathrm{Ga}} \mathrm{Ga}_{\mathrm{Sb}}\right)$, так и эффектом „очистки“ висмутом [35]. Следует отметить, что ширина спектра фотолюминесценции уменьшается, а интенсивность пика увеличивается с ростом кон-
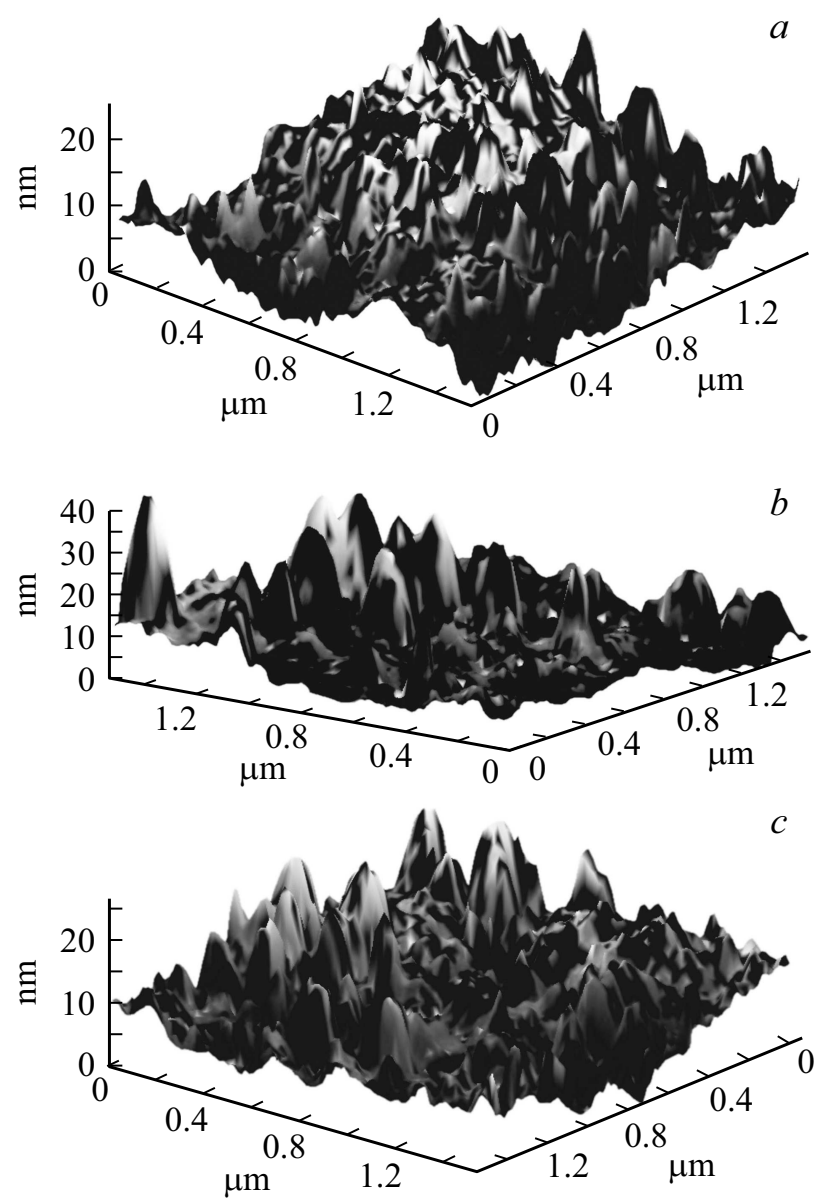

Рис. 5. Трехмерная морфология поверхности эпитаксиальных гетероструктур $\mathrm{Al}_{x} \mathrm{In}_{y} \mathrm{Ga}_{1-x-y} \mathrm{Bi}_{z} \mathrm{Sb}_{1-z} / \mathrm{GaSb}$ постоянного состава $(z=0.4): a-G=40 \mathrm{~K} / \mathrm{cm} ; b-G=100 \mathrm{~K} / \mathrm{cm}$ и варизонных структур; $c-G=40 \mathrm{~K} / \mathrm{cm}$.
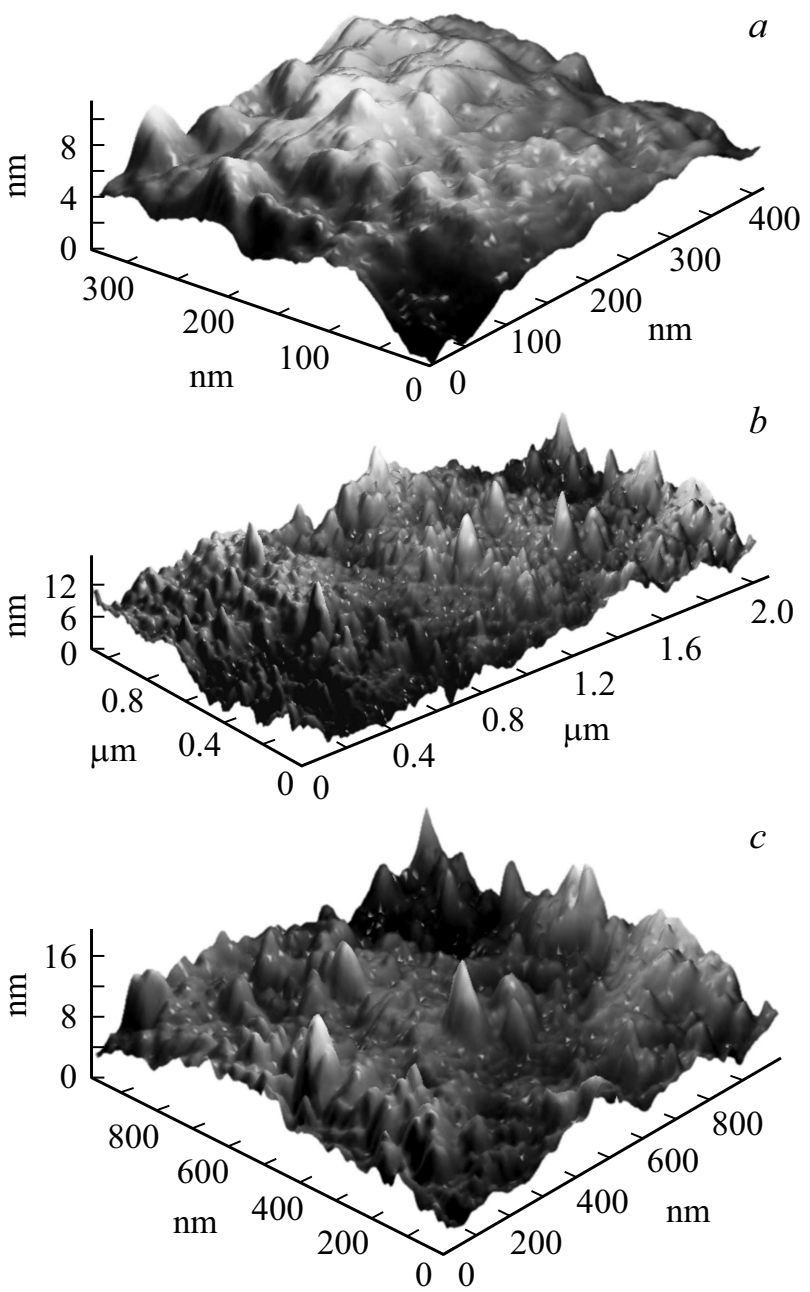

Рис. 6. Трехмерная морфология поверхности эпитаксиальных гетероструктур $\mathrm{Al}_{x} \mathrm{In}_{y} \mathrm{Ga}_{1-x-y} \mathrm{Bi}_{z} \mathrm{Sb}_{1-z} / \mathrm{GaSb}$ постоянного состава $(G=40 \mathrm{~K} / \mathrm{cm}): a-z=0.4, b-z=0.3, c-z=0.2$.

центрации висмута. Это косвенно свидетельствует о повышении структурного совершенства гетероструктур AlInGaBiSb/GaSb.

Экспериментальные исследования показали, что поверхность выращенной эпитаксиальной пленки AlInGaBiSb имеет шероховатость от 10 до $40 \mathrm{~nm}$ (рис. 5,6). Шероховатость поверхности гетероструктур $\mathrm{AlInGaBiSb} / \mathrm{GaSb}$ зависит от параметров процесса роста и концентрации висмута в твердом растворе. Как и следовало ожидать для гетероструктур $\mathrm{AlInGaBiSb} / \mathrm{GaSb}$ постоянного состава шероховатость ниже, чем у варизонных гетероструктур (рис. 5,a,c). Параметры шероховатости $R_{a}$ и $R_{z}$ также зависели от градиента температуры, увеличиваясь с повышением $G$ (рис. $5, a, b)$. С увеличением висмута в гетероструктурах шероховатость уменьшается (рис. $6, a-c$ ). Следовательно, качество поверхности определяется зависимостью параметров структурного совершенства $\left(\mathrm{V}_{\mathrm{Ga}} \mathrm{Ga}\right.$ sb и $\left.\sigma\right)$ от условий роста и концентрации висмута. Выявлены оптимальные условия роста с высоким структурным 
совершенством и качеством поверхности эпитаксиальных пленок AlInGaBiSb на подложках $\mathrm{GaSb}$ $10 \leq G \leq 30 \mathrm{~K} / \mathrm{cm}, \quad 60 \leq l \leq 100 \mu \mathrm{m}$, и температурный интервал $773 \leq T \leq 873 \mathrm{~K}$, концентрация висмута $0.3-0.4$ mol. frac.

\section{4. Заключение}

Показано, что висмут, замещая в антимониде галлия $\mathrm{Sb}$ в подрешетке сурьмы, уменьшает вероятность образования антиструктурных дефектов $\mathrm{V}_{\mathrm{Ga}} \mathrm{Ga}_{P \mathrm{Sb}}$ и снижает отклонение состава твердого раствора AllnGaBiSb от стехиометрического. Интенсивность люминесценции увеличивается, а ширина спектра фотолюминесценция уменьшается с ростом концентрации Ві в гетероструктурах AlInGaBiSb/GaSb, что говорит о повышении интегрального структурного совершенства гетероструктур.

Установлено, что монотонное смещение основного пика фотолюминесценции варизонных структур $\mathrm{AlInGaBiSb} / \mathrm{GaSb}$ в область малых энергий при увеличении содержания Вi в эпитаксиальных слоях обусловлено уменьшением ширины запрещенной зоны пленок AlInGaBiSb.

Основными технологическими параметрами, определяющими качество поверхности, структурные и люминесцентные свойства тонкопленочных гетероструктур $\mathrm{Al}_{x} \mathrm{In}_{y} \mathrm{Ga}_{1-x-y} \mathrm{Bi}_{z} \mathrm{Sb}_{1-z} / \mathrm{GaSb}$, являются состав, толщина жидкой зоны, температура и его градиент.

\section{Список литературы}

[1] P.V. Seredin, A.V. Glotov, A.S. Lenshin, I.N. Arsentyev, D.A. Vinokurov, T. Prutskij, H. Leiste, M. Rinke. Semiconductors 48, 21 (2014).

[2] H.Z. Song, M. Hadi, Y. Zheng, B. Shen, L. Zhang, Z. Ren, R. Gao, Z.M. Wang. Nanoscale Res. Lett. 12, 128 (2017).

[3] S.E. Gulebaglan, E.K. Dogan, M. Aycibin, M.N. Secuk, B. Erdinc, H. Akkus. Cent. Eur. J. Phys. 11, 1680 (2013).

[4] A.G. Gladyshev, I.I. Novikov, L.Ya. Karachinsky, D.V. Denisov, S.A. Blokhin, A.A. Blokhin, A.M. Nadtochiy, A.S. Kurochkin, A.Yu. Egorov. Semiconductors 50, 1186 (2016).

[5] D.A. Vinokurov, V.A. Kapitonov, A.V. Lyutetskiy, D.N. Nikolaev, N.A. Pikhtin, S.O. Slipchenko, A.L. Stankevich, V.V. Shamakhov, L.S. Vavilova, I.S. Tarasov. Semiconductors 46, 1321 (2012).

[6] V.V. Shamakhov, D.N. Nikolaev, A.V. Lyutetskiy, K.V. Bakhvalov, M.G. Rastegaeva, S.O. Slipchenko, N.A. Pikhtin, I.S. Tarasov. Semiconductors 48, 373 (2014).

[7] F. Schättiger, D. Bauer, J. Demsar, T. Dekorsy, J. Kleinbauer, D.H. Sutter, J. Puustinen, M. Guina. Appl. Phys. B 106, 605 (2012).

[8] V.D. Rumyantsev, A.V. Chekalin, D.A. Malevskiy, A.N. Panchak, N.A. Sadchikov, V.M. Andreev, N.Y. Davidyuk, A.L. Luque. IEEE J. Photovoltaics 5, 1715 (2015).

[9] A. Luque, I. Ramiro, P. Garcia-Linares, E. Antolin, A. Marti, A. Panchak, A. Vlasov, V. Andreev, A. Mellor. IEEE J. Photovoltaics 5, 1074 (2015).
[10] M.A. Mintairov, N.A. Kalyuzhnyy, V.V. Evstropov, V.M. Lantratov, S.A. Mintairov, M.Z. Shvarts, V.M. Andreev, A. Luque. IEEE J. Photovoltaics 5, 1229 (2015).

[11] R.V. Levin, A.E. Marichev, M.Z. Shvarts, E.P. Marukhina, V.P. Khvostikov, B.V. Pushnyi, V.M. Andreev, M.N. Mizerov. Semiconductors 49, 700 (2015).

[12] M.A. Mintairov, V.V. Evstropov, S.A. Mintairov, M.Z. Shvarts, N.K. Timoshina, N.A. Kalyuzhnyy. Semiconductors 49, 668 (2015).

[13] V. Khvostikov, N. Kalyuzhnyy, S. Mintairov, N. Potapovich, M. Shvarts, S. Sorokina, A. Luque, V. Andreev. AIP Conf. Proc. 1616, 21 (2014).

[14] N.A. Kalyuzhnyy, V.V. Evstropov, V.M. Lantratov, S.A. Mintairov, M.A. Mintairov, A.S. Gudovskikh, A. Luque, V.M. Andreev. Int. J. Photoenergy 2014, 836284 (2014).

[15] В.В. Кузнецов, Л.С. Лунин, В.И. Ратушный. Гетероструктуры на основе четверных и пятерных твердых растворов соединений $\mathrm{A}^{\mathrm{III}} \mathrm{B}^{\mathrm{V}}$. СКНЦ ВШ. Ростов н/Д (2003). 375 с.

[16] В.Н. Лозовский, Л.С. Лунин, А.В. Благин. Градиентная жидкофазная кристаллизация многокомпонентных материалов. СКНЦ ВШ. Ростов н/Д (2003). 374 с.

[17] L. Wang, L. Zhang, L. Yue, D. Liang, X. Chen, Y. Li, P. Lu, J. Shao, S. Wang. Shumin. Cryst. 7, 63 (2017).

[18] G.B. Stringfellow. J. Cryst. Growth 468, 11 (2017).

[19] P. Wang, W. Pan, X. Wu, J. Liu, C. Cao, S. Wang, Q. Gong. Nanoscale Res. Lett. 11, 280 (2016).

[20] W. Pan, L. Zhang, L. Zhu, Y. Song, Y. Li, C. Wang, P. Wang, X. Wu, F. Zhang, J. Shao, S. Wang. Semicond. Sci. Technology 32, 015007 (2017).

[21] D.F. Reyes, F. Bastiman, C.J. Hunter, D.L. Sales, A.M. Sanchez, J.P.R. David, D. González. Nanoscale Res. Lett. 9, 23 (2014).

[22] D.L. Alfimova, L.S. Lunin, M.L. Lunina. Inorganic Mater. 50, 113 (2014).

[23] В.Н. Лозовский, Л.С. Лунин, Т.А. Аскарян. Неорган. материалы 25, 1778 (1989).

[24] B.M. Sinel'Nikov, M.L. Lunina. Inorganic Mater. 48, 877 (2012).

[25] A.V. Blagin, D.P. Valyukhov, R.V. Pigulev, I.M. Khabibulin, L.S. Lunin. Inorganic Mater. 44, 793 (2008).

[26] K. Chakir, C. Bilel, M.M. Habchi, A. Rebey. Superlattices Microstructures 102, 56 (2017).

[27] F. Sarcan, Ö. Dönmez, K. Kara, A. Ero, E. Akalın, M.Ç. Arıkan, H. Makhloufi, A. Arnoult, C. Fontaine. Nanoscale Res. Lett. 9, 119 (2014).

[28] A. Rogalski. Opto-electron. Rev. 16, 458 (2008).

[29] C.A. Wang, H.K. Choi, S.L. Ransom. Appl. Phys. Lett. 75, 1305 (1999).

[30] S.A. Karandashev, B.A. Matveev, M.A. Remennyi, A.A. Shlenskii, L.S. Lunin, V.I. Ratushnyi, A.V. Koryuk, N.G. Tarakanova. Semiconductors 41, 1369 (2007).

[31] В.Н. Лозовский, Л.С. Лунин, В.П. Попов. Зонная перекристаллизация градиентом температуры полупроводниковых материалов. Металлургия, М. (1987). 232 с.

[32] Д.Л. Алфимова, Л.С. Лунин, М.Л. Лунина, А.С. Пащенко, С.Н. Чеботарев. Кристаллография 62, 137 (2017).

[33] Д.Л. Алфимова, Л.С. Лунин, М.Л. Лунина, А.С. Пащенко, С.Н. Чеботарев. Неорган. материалы 53, 33 (2017).

[34] М.Г. Мильвидский, В.Б. Освенский. Структурные дефекты в эпитаксиальных слоях полупроводников. Металлургия, M. (1985). $160 \mathrm{c}$.

[35] В.Г. Зиновьев, А.И. Моргун, В.Б. Уфимцев. Неорган. материалы 29, 177 (1993).

Редактор К.В. Емцеев 